\title{
A Methodology for the Estimation of Microplastic Concentration in Relation to the Meteorological Forcing and WWTPs Effluents in Urban Coastal Areas
}

\author{
S. Anastasiou \\ Department of Environmental Engineering, Democritus University of Thrace, Xanthi, 67100, Greece
}

Received 29 September 2020; Accepted 10 October 2020

\begin{abstract}
The study of the urban coastline is of great significance for understanding the impacts of human activities on the marine environment. Only recently the emission of microplastics is starting to be considered as a threat to aquatic and terrestrial ecosystems and currently, little information on this topic is available. The present study focuses on the development of a methodology based on the implementation of the hydrodynamic circulation model ELCOM (Estuary and Lake Computer Model) for the estimation of microplastics distribution in Kavala Gulf coastline. The approach aims to include the effects of the high seasonal touristic activity and consequent large fluctuations in wastewater treatment plants (WWTPs) discharge rates. Parameters such as microplastic concentration, effluent flow rate and temperature, meteorological forcing and scalars at the boundaries were applied and the simulation was designed to cover the entire 2006 in order to include an approximation of the seasonal 3D dispersion patterns. The microplastic concentration was estimated based on the suspended particulate matter (SPM) concentration measurements applying the approach of [1]. The physical and chemical parameters of the particles were assumed to conform with the assumptions of [2]. The results showed a strong correlation between the microplastics dispersion patterns, the wind climate and the seasonal increase in population during the summer. Microplastic concentrations reached up to $0.185 \mu \mathrm{g} / \mathrm{l}$ in the WWTPs adjacent coastline in correspondence to the beaches with the highest touristic activity. The periodical formation of anticyclonic flows resulted in a net transport towards the center of the gulf and an increase in microplastic concentration in the bottom layer. On the other hand, the simulation showed that considerable quantities of microplastics tend to be transported outside the study area and far from the coastline in deeper waters.
\end{abstract}

Keywords: microplastics, WWTP, ELCOM, hydrodynamic circulation, meteorological forcing

\section{Introduction}

The presence of microplastics, especially in coastal areas, have been recognized worldwide as an emerging environmental issue ([3], [4], [5], [6]) of increasing concern but only recently has begun to receive international attention by the academic community and the European Union ([7], [8], [9]). Ecotoxicological effects of microplastics on marine, invertebrates, and plants are well documented ([10], [11], [12], [13]), however, especially on the subject of the toxicity and the transfer mechanism to the coastal benthic communities and to the human population the data are limited.

Several experiments showed that microplastics could be adsorbed, ingested and accumulated in larger marine fauna by trophic transfer from prey to predator, such as musselconsuming crabs [14]. Furthermore, organic pollutants could be adsorbed onto microplastic particles ([15], [16], [17], [18]) leading to a potential enhancement of their effective uptake and toxicity ([19], [20], [21]). For instance, they can potentially function as vectors for pollutant transfer to living organisms through interaction with metallic toxicants and other toxic trace elements such as Cadmium ([22], [23], [24]).

The term microplastics has been given several definitions in literature, but the one prevailing is given by Galgani et al.,

\footnotetext{
E-mail address: sotiriaanastasiou@yahoo.com

ISSN: 1791-2377 @ 2020 School of Science, IHU. All rights reserved.

doi:10.25103/jestr. 135.13
}

2013, [25] which refers to particles of $<5 \mathrm{~mm}$ in diameter (upper limit) based on its common usage in existing monitoring programs.

Microplastics are distinguished also in primary and secondary. They are described as primary when the particles were originally manufactured to be that size (e.g. microbeads, plastic pellets, nurdles, plastic fibers) and secondary when the particles resulted from the breakdown of larger items (fishing nets, plastic litter). Most of the losses of primary microplastics (98\%) are generated from land-based activities [26] with the higher concentrations found in water and sediment near or downstream of wastewater treatment plants (WWTP), [27].

At a global-level two microplastics assessments (GESAMP, 2015 and 2016) and a recent report [28] were made available in an effort to harmonize research and monitoring. The methods applied and reviewed, comprise mainly in situ sampling techniques and the application of mathematical simulation models in order to comprehend the influence of the physical processes in the dispersion and accumulation patterns. Those patterns are primarily defined by environmental factors such as wave, currents [29], tides, cyclones, wind directions ([30], [31], [32], [33]), and river hydrodynamics ([34], [35], [36]).

In particular, the distribution of microplastics in the water column is highly influenced by the vertical transport and other processes that include sinking due to ingestion-egestion [37], marine snow [38] and/or biofouling [39] as well as mixing [40]. After several attempts to simulate the dispersion mechanisms with the application of specific vertical mixing 
models [41] or theoretical turbulence processes [42] some authors suggested that a well-studied suspended sediment transportation systems [43], could offer a more established framework for modelling suspended microplastic transportation.

The purpose of this research is to propose a methodological approach by applying an already validated and calibrated hydrodynamic circulation model in order to study the spatiotemporal distribution of microplastics in the study area based on the sampling results of 2 WWTP's effluents and the meteorological forcing. The method has already been applied for the simulation of the suspended particulate matter dispersion patterns in the adjacent coastal zone giving very accurate predictions of the SPM concentrations in the water column in relation to the wind climate, meteorological forcing and hydrodynamic circulation.

\section{Study area}

The Gulf of Kavala is located in northern Greece in the Thracian Sea across from the island of Thasos. Is the second in size semi-enclosed coastal water body of the Thracian Sea, which is part of the North Aegean Sea's continental shelf (Fig. 1), [44].

East and northwest winds are dominant during the winter period having frequencies of $7 \%$ and $10 \%$, respectively. The area is micro-tidal, with the tidal range varying between 0.12 $\mathrm{m}$ during neap tides and $0.30 \mathrm{~m}$ during spring tides under the prevalence of the semi-diurnal (M2) tidal constituent. The input of Black Sea Water (BSW) through the Dardanelles governs the surface dynamics of Kavala Gulf by supplying low salinity (29-34 ppt), nutrient-rich BSW, which occupies the surface layer of the water column $(20-40 \mathrm{~m})$, [45].

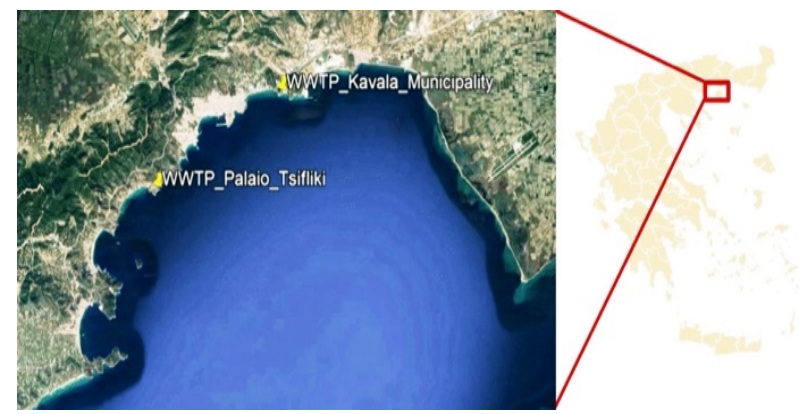

Fig. 1. Satellite image of the study area - Kavala Gulf - and the location of the two Wastewater Treatment Plants.

The most densely populated zone, the city of Kavala, is situated in the north part of the gulf with 54,027 permanent residents according, to the latest census (2011), which makes it the 4th largest city in the region. Other important settlements are Paleo Tsifliki (Palio) (2,195 permanent residents) and Nea Peramo. (3,532 permanent residents) located along the west coastline. In Kavala Gulf there are a total of 2 WWTP that treat the urban wastewater of a) the city of Kavala and b) the settlement of Paleo Tsifliki.

The first WWTP was designed in the late 1980's, is operational since the early 1990 's and has the potential to receive up to $12,000 \mathrm{~m}^{3}$ of urban wastewater daily. Today after the facilities' expansion works the WWTP of the city of Kavala can receive $20.000 \mathrm{~m}^{3}$ of effluents daily, covering the needs of approximately 80,000 inhabitants and the increased demand during the summer season.
The settlement of Paleo Tsifliki, which administratively belongs to the municipality of Kavala, is located $8 \mathrm{~km}$ southwest of the city center and extends along the coast for about $4 \mathrm{~km}$. The area is characterized by high touristic activity during the summer months, which means a large population growth during this period. The WWTP has been operating since June 1998 and is located at the eastern limit of the settlement.

Before the construction of the WWTP in Paleo Tsifliki, a study for the projection of the population for the next 30 year that was implemented predicting an increase in the population of about 5 times. Based on that results, the WWTP in Paleo Tsifliki, was built to accommodate a population of 12,000 residents during the summer months, for the next 10 years with an increase of 18,000 residents for the next 30 years. During the summer months the WWTP was designed to receive $87 \mathrm{~L} / \mathrm{sec}$ to $119 \mathrm{~L} / \mathrm{sec}$ during the peak of the touristic season. The water effluents after being processed are channeled to the coastal area of Palio Bay (part of "NATURA 2000" network, code GR 1150009).

Both WWTPs were built by the Municipal Water Supply and Sewerage Company of Kavala (DEYAK) and the values of specific chemical parameters in the wastewater, after being processed, they conform to several EU Directives and the national legislation (e.g. BOD5 $<20 \mathrm{ppm}, \mathrm{COD}<60 \mathrm{ppm}$ Suspended solids $<30 \mathrm{ppm}$ ).

In both Kaval and Paleo Tsifliki WWTPs, the temperature of the effluents, according to measurements carried out by DEYAK, is for the most part of the year, with the exception of summer, higher than the ambient temperature because it is affected by the high wastewater temperatures (with values ranging between $10{ }^{\circ} \mathrm{C}$ and $22{ }^{\circ} \mathrm{C}$ ), a fact that was taken into account and included in the input data of the hydrodynamic model. The statistical processing of the measurements taken by DEYAK showed that between the years 2000-2008 the concentration of suspended solids entering the plants was on average approximately equal to $200 \mathrm{mg} / \mathrm{l}$ or $5600 \mathrm{~kg} / \mathrm{d}$ while at the exit the values ranged between $10 \mathrm{~kg} / \mathrm{d}$ and $200 \mathrm{~kg} /$ day. The maximum allowable limit according to the WWTP design is $35 \mathrm{mg} / \mathrm{l}$ in suspended solids.

\section{Materials and methods}

\subsection{Model description}

ELCOM (Estuary and Lake Computer Model) is a threedimensional hydrodynamic model, developed by the Centre for Water Research, that can be applied for the simulation of current velocity, temperature, salinity distribution and variation in water bodies such as estuaries, lakes and coastal areas. ELCOM solves the unsteady, 3D-Reynolds averaged hydrostatic Navier-Stokes, Bussinesq equations and the scalar transport equations taking into consideration the external environmental forcing. For the calculation of the vertical turbulent transport in ELCOM a mixing model is applied and the heat exchange through the water surface is governed by standard bulk transfer models.

The quadratic Euler-Lagrange discretization for advection of momentum is applied with a conjugate-gradient solution for the free-surface height. Passive and active scalars (i.g. tracers, salinity and temperature) transport are solved based on a conservative ULTIMATE QUICKEST approach [46].

The core equations in ELCOM are:

Momentum transfer equation: 


$$
\begin{aligned}
& \frac{\partial U_{a}}{\partial t}+U_{j} \frac{\partial U_{a}}{\partial x_{j}}=-g\left(\frac{\partial \eta}{\partial x_{a}}+\frac{1}{\rho_{0}} \frac{\partial}{\partial x_{a}} \int_{z}^{\eta} \rho^{\prime} d z\right) \\
& +\frac{\partial}{\partial x_{1}}\left(v_{1} \frac{\partial U_{a}}{\partial x_{1}}\right)+\frac{\partial}{\partial x_{2}}\left(v_{2} \frac{\partial U_{a}}{\partial x_{2}}\right)+\frac{\partial}{\partial x_{3}}\left(v_{3} \frac{\partial U_{a}}{\partial x_{3}}\right)-\varepsilon_{\alpha \beta} f U_{\beta}
\end{aligned}
$$

Continuity equation

$$
\frac{\partial U_{j}}{\partial x_{j}}=0
$$

Momentum Boundary Conditions -Free Surface

$$
\frac{\partial U_{a}}{\partial x_{3}}=0
$$

Momentum Boundary Conditions -Bottom and Sides

$$
U_{i}=0
$$

Transport of Scalars:

$$
\begin{aligned}
& \frac{\partial C}{\partial t}+\frac{\partial\left(C U_{j}\right)}{\partial x_{j}}=\frac{\partial}{\partial x_{1}}\left(\kappa_{1} \frac{\partial C}{\partial x_{1}}\right)+ \\
& +\frac{\partial}{\partial x_{2}}\left(\kappa_{2} \frac{\partial C}{\partial x_{2}}\right)+\frac{\partial}{\partial x_{3}}\left(\kappa_{3} \frac{\partial C}{\partial x_{3}}\right)+S_{c}
\end{aligned}
$$

Scalars Boundary Conditions:

$\frac{\partial C_{a}}{\partial x_{j}}=0$

Free surface Evolution:

$$
\frac{\partial \eta}{\partial t}=-\frac{\partial}{\partial x_{a}} \int_{0}^{\eta} u_{a} d z
$$

Free Surface wind shear:

$$
\left(u_{*}\right)_{a}^{2}=C_{10} \frac{\rho_{\text {air }}}{\rho_{\text {water }}}\left(W_{\beta} W_{\beta}\right)_{1 / 2} W_{a},
$$

Wind momentum input:

$$
\frac{\partial U_{a}}{\partial t}=\frac{\left(U_{*}\right)_{a}^{2}}{h}
$$

\section{Where:}

$\mathrm{j}=1,2,3$ are the three space components (axes $\mathrm{x}, \mathrm{y}, \mathrm{z}$ ) $\alpha, \beta=$ the two space components $(\mathrm{x}, \mathrm{y})$

$\rho_{0}=$ reference density

$\rho^{\prime}=$ in-situ density anomaly

$f=$ Coriolis constant

$\eta=$ Reynolds-averaged free-surface elevation
$C_{10}=$ bulk wind stress coefficient for wind values at $10 \mathrm{~m}$ from the sea surface.

$W_{\beta}, W_{a}=$ wind velocity components (directions $\alpha, \beta$ )

$\left(U_{*}\right)_{a}=$ Wind shear velocity on the free surface in direction $\alpha$

$\left(u_{*}\right)_{a}=$ Wind Shear velocity in direction $\alpha$

$\kappa_{i}=$ eddy diffusivity coefficient

$S_{c}=$ Schmidt number

$v j=$ Eddy viscosity coefficient,

The model has been applied in several cases for different types of water bodies giving very good results ([47], [48], [49], [50], [51], [52], [53]).

Regarding the area of North Aegean and Thracian Sea the model has been applied (Laboratory of Ecological Engineering - DUTH) in order to describe and predict the hydrodynamic circulation in very large areas [54] or smaller ones such as gulfs and straits [55]. The model in those cases was calibrated and validated based on in situ measurements of different oceanographic stations and satellite imagery proving to be a useful tool for the description and prediction of the hydrodynamic conditions and parameters. ELCOM was also coupled with the wave model SWAN for the investigation of the coastal surface currents effect on the wave propagation direction [56].

\subsection{Model implementation}

The ELCOM hydrodynamic simulation model was implemented in the area covering Kavala Gulf between $40^{\circ}$ $57^{\prime} 27.11^{\prime \prime} \mathrm{N}$ and $24^{\circ} 17^{\prime} 18.87^{\prime \prime} \mathrm{E}$ and it was discretized into a uniform horizontal bilinear grid consisting of $100 \mathrm{~m} \times 100 \mathrm{~m}$ orthogonal cells (Fig. 2). The water column depth at each cell was determined using the 1:50,000 bathymetric chart vectorized in GIS environment and corrected with the updated bathymetric estimations provided by EMODnet. The maximum depth in the study area corresponding to $48 \mathrm{~m}$ was discretized in 6 vertical layers, of variable thickness, starting from the surface $(\mathrm{dz}=1.2 \mathrm{~m})$ and increasing gradually towards the bottom. Model boundary conditions involved hydrological, meteorological and tidal forcing.

The tidal forcing at the grid boundaries was given as the temporal and spatial surface height variation. The values were obtained from a previous and ongoing implementation of ELCOM concerning the entire Aegean Sea [57] and involved 5 hours' time series for the entire 2006 (1/1/2006 00:00 31/12/2006 21:00) (Table 2). The time series of salinity and temperature at the boundaries for the entire year were obtained also from the model results of the Aegean Sea simulation implemented as average daily values. The northern and partially the eastern side of the grid were considered as the open boundaries.

Table 2. Basic statistical parameters of the meteorological variables implemented in ELCOM runs - time period 1/1/2006-31/12/2006.

\begin{tabular}{l|l|l|l}
\hline N total $=\mathbf{2 9 1 3}$ & Average & Minimum & Maximum \\
\hline AIR_TEMP & 14.81593 & -8.2 & 33.7 \\
REL_HUM & 0.69683 & 0.34 & 0.968 \\
SOLAR_RAD & 209.8399 & 0 & 873.2 \\
ATM_PRESS & 100302.2 & 98250 & 102280 \\
RAIN & $8.84 \mathrm{E}-04$ & 0 & 0.02697 \\
CLOUDS & 0.40828 & 0 & 1
\end{tabular}




\section{\begin{tabular}{l|l|l|l} 
WIND_SPEED & 4.05466 & 0.051 & 15.536
\end{tabular}}

BATHYMETRY

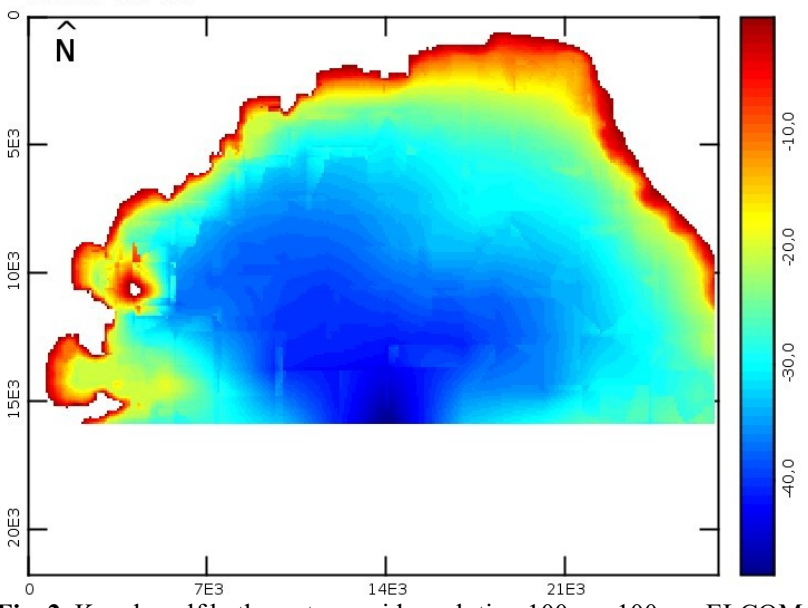

Fig. 2. Kavala gulf bathymetry - grid resolution 100m x 100m - ELCOM model implementation.

Meteorological forcing included the synoptic daily datasets of solar radiation intensity, atmospheric temperature, atmospheric relative humidity, precipitation, cloud coverage, wind speed and direction acquired from the NOAA database http://ready.arl.noaa.gov/READYamet.php) and based on satellite imagery and the GDAS meteorological model results. The outflow rate and the water temperature for both WWTP were taken from DEYAK measurements that were conducted approximately every 3 days and the gaps between data were interpolated applying the Expectation-Maximization method in SPSS based on the overall data time series covering the time period between 2002 and 2008.

The microplastics concentration in the WWTPs effluents was calculated based on the SPM measurements and the results obtained from several researchers and mainly based on the research of Conley et. al, 2019, [1] (Tab. 1). The approach of Van Wezel et. al., 2016, [2] was selected for the assumptions made for the microplastics parameters. The microplastic particles were assumed to be of cubical shape, and the variation in density of commonly used microplastics (polyethylene, polypropylene, PVC, polystyrene, polyurethane, and polyethylene terephthalate) was taken into consideration. The average density was calculated equal to 1 $\mathrm{gr} / \mathrm{cm}^{3}$ signifying a nearly neutral buoyancy for the particles. Processes such as biofouling and ingestion from marine biota were not included.

Table 1. Predicted concentrations of microplastics in WWTP effluents according to the approach implemented by Conley et al.

\begin{tabular}{l|l}
\hline Particle effluent & 70 \\
Particle size $(\mu \mathrm{m})$ & 1000 \\
Particle volume $\left(\mathrm{cm}^{3}\right)$ & $1 \times 10^{-9}$ \\
$\begin{array}{l}\text { Average density }\left(\mathrm{g} / \mathrm{cm}^{3}\right) \\
\text { Predicted concentration } \\
(\mu \mathrm{g} / \mathrm{L})\end{array}$ & 1 (neutral Buoyancy) \\
\hline
\end{tabular}

The set of assumptions applied in this case is taking into consideration also the pro-capita use of different microplastic sources from the population in the study area. This so-called intermediate scenario is considered the most reliable for European countries because of the EC directives regarding the maximum allowed solid suspended concentrations in the WWPTs effluents.

The model results were registered with a time step of 6 hours covering the entire duration of 2006. The year was selected because of the presence of the highest concentration in BOD, COD, SPM based on DEYAK measurements covering the time period between 2002 and 2008.

\subsection{Model input parameters and calibration}

The scalar parameters at the boundaries and the parameters describing the meteorological forcing were processed and statistically analyzed.

For the study area, the water temperature varies between $13{ }^{\circ} \mathrm{C}$ during February and March and $26{ }^{\circ} \mathrm{C}$ during August and September with an average value of $18.48{ }^{\circ} \mathrm{C}$. Salinity decreases during spring months reaching minimum values during the beginning of the summer season (34 ppt) and maxima during the winter months (37.3 ppt). The free surface height fluctuates during the entire year between $0.7 \mathrm{~m}$ (flood) and $-0.51 \mathrm{~m}$ (ebb) with an average of $0.36 \mathrm{~m}$ and $-0.24 \mathrm{~m}$ respectively (Fig. 3).

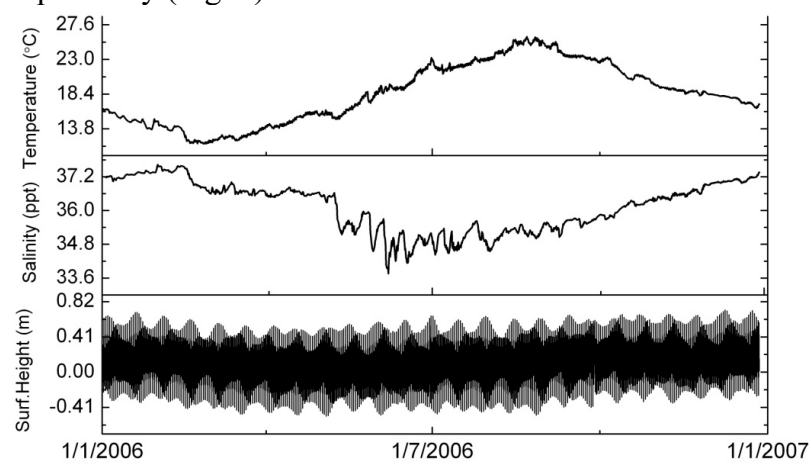

Fig. 3. South and southeast boundary parameters input data (scalars) in ELCOM implementation for Kavala gulf - time period $1 / 1 / 2006$ $31 / 12 / 2006$.

During 2006 the air temperature reached the highest values during August and the lowest during February preceding in both cases the respective fluctuations in water temperature for about a month. The maximum wind speed $(15.5 \mathrm{~m} / \mathrm{s})$ and persisting high cloud coverage percentage are observed also during February and March (Fig. 4).

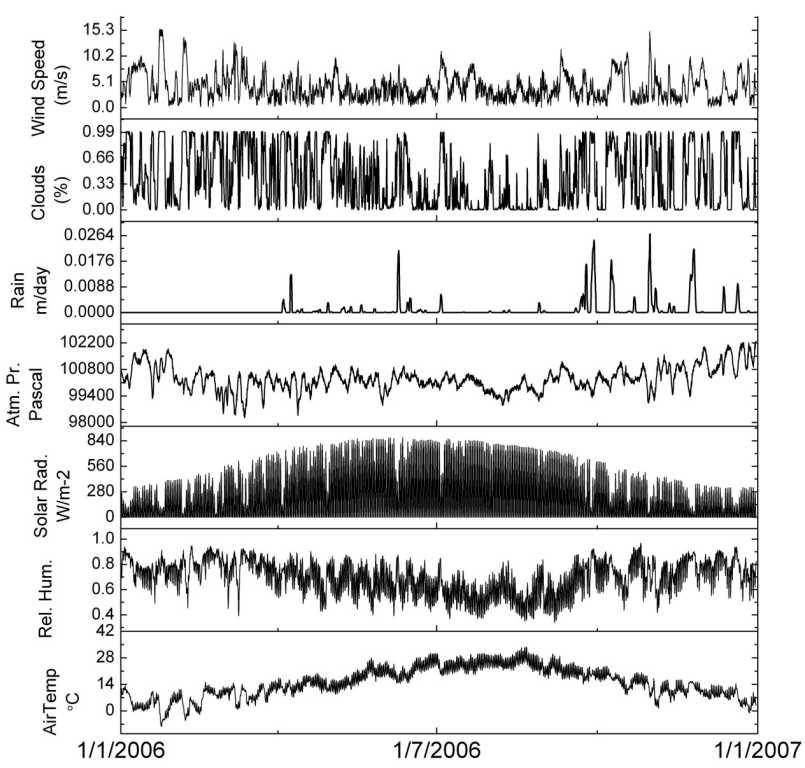

Fig. 4. Meteorological forcing input data in ELCOM implementation for Kavala gulf - time period1/1/2006-31/12/2006 (NOAA), (Kamidis et al. 2011) [57]. 
The winds during the entire year were blowing mainly from northeast directions (frequency $=43 \%$ ) in accordance with the etesian wind patterns present in the study area (Fig. $5)$.

Wind Speed $(\mathrm{m} / \mathrm{s})$ - Direction Frequency,

Year 2006, ELCOM Input $\mathrm{N}$

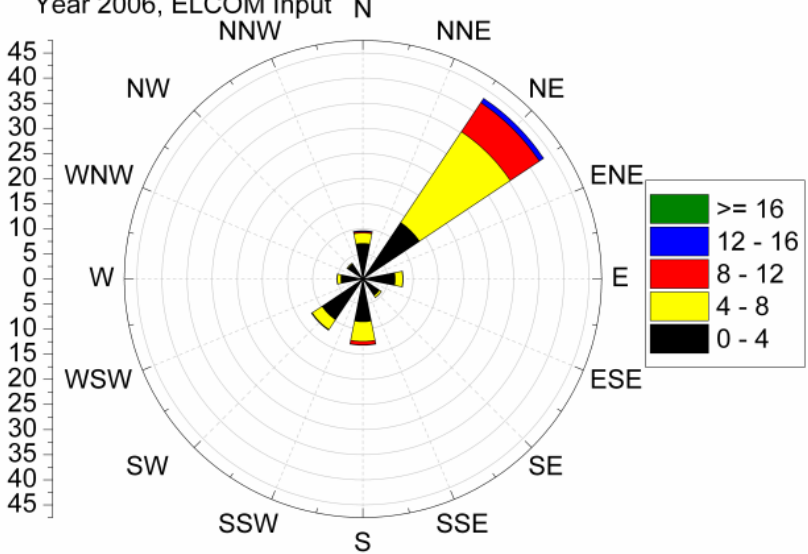

Fig. 5. Wind speed and direction frequencies analysis in Kavala gulf during the year 2006 .

The highest microplastic concentrations in the Kavala WWTP effluents were observed during the winter and spring months reaching up to $18 \mu \mathrm{g} / \mathrm{l}$ with larger fluctuations in comparison with the rest of the year during which the concentrations were more stable with an average of $11 \mu \mathrm{g} / \mathrm{l}$. On the other hand, the microplastics concentrations in the Paleo Tsifliki WWTP effluents increased starting from early summer, with an average of $2.9 \mu \mathrm{g} / \mathrm{s}$ and maxima $3.8 \mu \mathrm{g} / \mathrm{l}$, and returned to the base values in late October (1.6 $\mu \mathrm{g} / \mathrm{l})$, (Fig. 6).

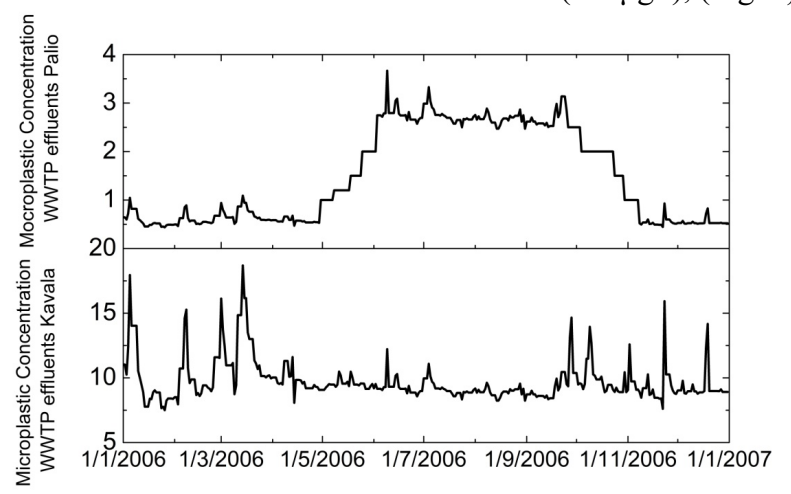

Fig. 6. Microplastics concentration in $\mu \mathrm{g} / 1$ in the effluents of both Kavala and Paleo Tsifliki (Palio) WWTPs.

ELCOM hydrodynamic model has been already calibrated on several occasions for the broader area of the Thracian and Aegean Sea in previous implementations based on measurements carried out by Triton monitoring station (DUTH). The model results concerning the hydrological circulation simulation, for the entire water column, were validated giving a rate of accuracy for current speed and direction of about $60 \%$. For the scalars, the model is considered to be even more precise in the order of approximately $80 \%$ regarding salinity and temperature. The model outputs were tested applying several statistical methods such as RMSE and mean Bias.

\section{Results and Discussion}

The hydrodynamic circulation in the surface layer of the study area is presented mainly in two different configurations due to the fact that the surface water from the north Aegean Sea, enters the study area, from two different directions throughout the year. In the first case, the surface currents enter the gulf from the southwest boundary and spread inside the gulf forming periodically an anticyclonic flow the range of which depends on the current and wind speed and direction (Fig. 7). This configuration starts forming during the spring months and lasts up until early summer when the Etesian winds are blowing in the area.
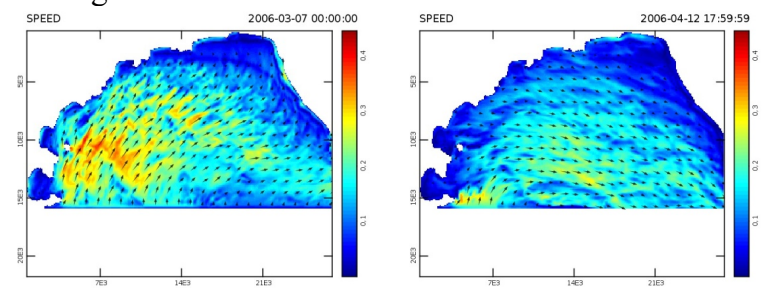

Fig. 7. Surface hydrodynamic circulation configuration inside Kavala gulf during the beginning of the spring months-ELCOM results 2006.

The second configuration appears periodically during autumn and winter when the surface currents at the boundary are entering from southeast directions and as a result a less pronounced cyclonic pattern is established at the center of the gulf in accordance with the stronger northeast winds (Fig. 8). In either case, the maximum surface current velocities are observed near the southwest boundary of the gulf reaching up to $0.4 \mathrm{~m} / \mathrm{s}$.
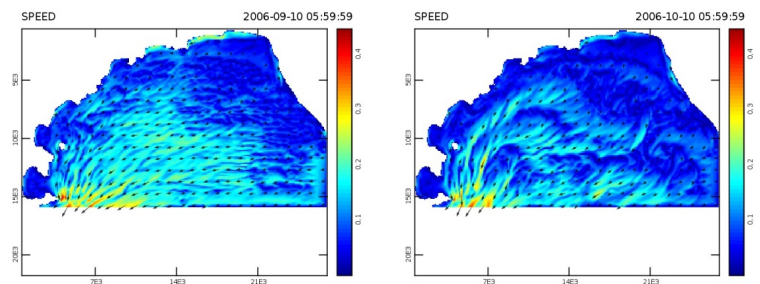

Fig. 8. Surface hydrodynamic circulation configuration inside Kavala gulf during the autumn months or in the presence of strong north winds during winter-ELCOM results 2006.

The bottom maximum current velocities are observed in the southwest sector of the gulf reaching values up to 0.3-0.4 $\mathrm{m} / \mathrm{s}$ independently of the general circulation configuration present in the study area (Fig. 8-9). When the surface currents enter the gulf from the southwest boundary the correspondent bottom currents present an approximately $90^{\circ}$ to $180^{\circ}$ shift in direction (counterclockwise) (Fig. 9a). When the surface currents exit the gulf (southwest boundary) the bottom circulation pattern seems to follow that of the surface especially near the coastal zone (Fig. 9b).
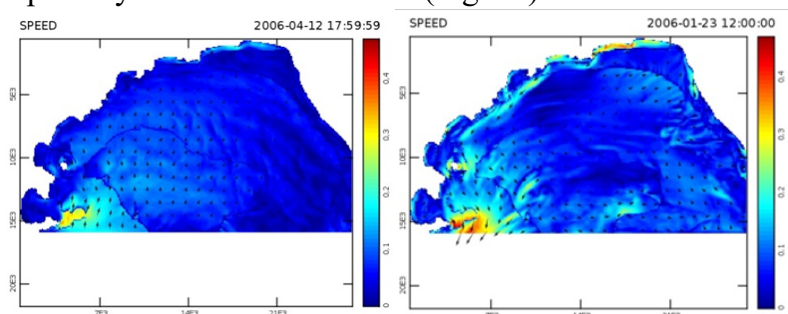

Fig. 9. a) Bottom currents pattern in Kavala gulf in correspondence to southwest superficial currents - ELCOM results 2006, b)Bottom currents pattern in Kavala gulf in correspondence to southeast superficial currents - ELCOM results 2006.

The sectors of the coastline with the higher surface current speeds seem to be those in which the WWTPs are situated. More precisely the northern sector corresponding to Kavala's coastline presents some of the maximum surface current 
velocities independently of the hydrodynamic circulation pattern inside the gulf. In the northwest sector, the coastline of Paleo Tsifliki is mostly influenced by the presence of highspeed surface currents parallel to the coastline.

The largest concentrations of microplastics are observed for almost the entire duration of the year near the port of Kavala and the adjacent western coastline extending up to Paleo Tsifliki with concentrations ranging between $0.048 \mu \mathrm{g} / 1$ and $0.185 \mu \mathrm{g} / \mathrm{l}$ (Fig. 10a). At the beginning of May, a distinct increase in the Paleo's WWTR outflow rate results in an increase in microplastics surface concentration in the immediate area reaching up to $0.08 \mu \mathrm{g} / \mathrm{l}$ due to the combined effluent quantities and the extension of the plum to the south and the center of the gulf (Fig. 10b).
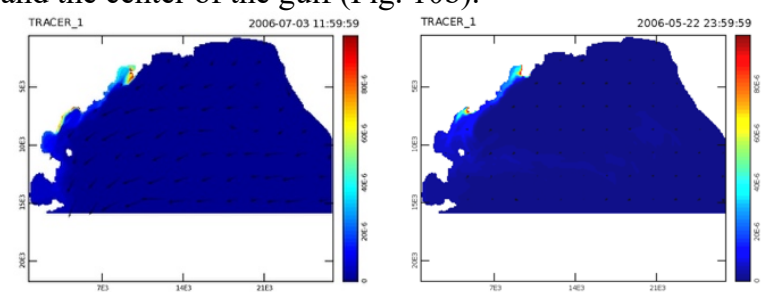

Fig. 10. a) Microplastics concentration and effluents plume formation during high speed surface currents coming from east - southeast directions, b) Microplastics concentration and effluents plume formation during low speed surface currents coming from east - southeast directions

The anticyclonic patterns are stronger covering a much larger area at the central part of the gulf transporting the microplastics for longer distance and creating periodically a larger dispersion at the surface throughout the entire study area and not only the central part. These patterns seem to be observed starting from October until December in correspondence with the strongest winds blowing in the area (Fig. 11).

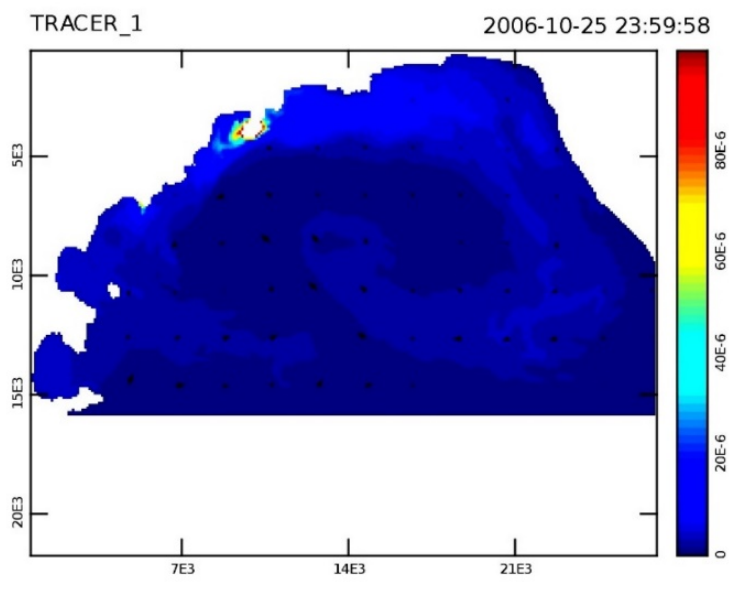

Fig 11. Microplastics concentration in the surface layer during the presence of anticyclonic flow patterns at the center of the gulf.

In absence of strong currents or winds or when the etesian winds are blowing the surface water from the Aegean Sea tends to enter and exit the gulf from throughout the entire length of the southern boundary at low velocities determined mainly by the tidal cycle pattern keeping the plum from both WWTP attached to the western coastline of the gulf for the most part of the year. At the beginning of October, the microplastics dispersion towards the eastern part of the gulf tends to increase reaching in some cases the eastern coastline.

In the bottom layer, the same pattern as in the surface layer seems to prevail except the fact that the plumes tend to detach from the western coastline and transport a significant amount of microplastics towards the center of the gulf for almost the entire duration of the year. The anticyclonic pattern near the bottom tends to form earlier in the year and seems to be more stable for longer periods of time. The periodical presence of stronger currents near the coastline tends to transport the microplastics for longer distances and in higher concentrations, reaching more frequently the eastern coastline having as a result a more pronounced dispersion though out the entire gulf.

Microplastic concentrations in the bottom layer seem to be of the same size class to those estimated for the surface layers due mainly to the fact that the model is implemented for neutral buoyancy with the exception of the eventual increase because of the vertical circulation patterns in the area that tend to create downwellings (Fig. 12).
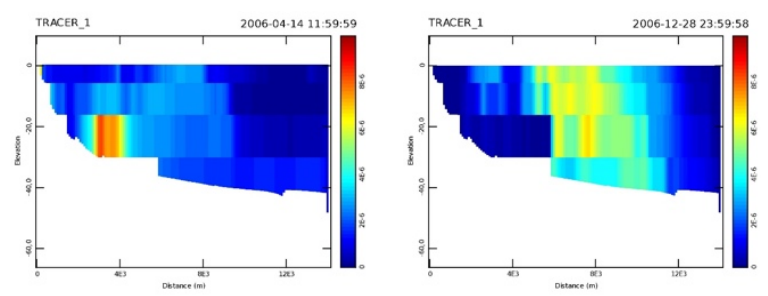

Fig. 12. Vertical profile (north-south direction) of microplastics concentration - central part of the gulf - during the presence of anticyclonic flow and the formation of small downwelling currents.

These vertical flow patterns can be observed mainly during the winter and spring months when the winds are blowing from north directions, parallel to the east and west coastline, and when the Ekman transport moves the surface layer in a direction $90^{\circ}$ to the wind towards the center of the gulf. The surface water from the eastern coastline that is transported at the center sinks transporting the microplastics at the bottom creating the conditions for their deposition and eventual accumulation.

\section{Conclusions}

The results show that the largest percentage of microplastic curried by the bottom currents are transported periodically at the center of the gulf or outside the study area towards deeper waters into the Thracian Sea resulting in a decrease of the total load for the coastline. At the same time, the surface hydrodynamic circulation tends to keep the large majority of microplastics near the coastline leading probably to a large temporary accumulation in shallow waters. The higher microplastic concentrations are observed in the water column between the Mean Sea Level and the 9-meter isobath in the western and partially north coastline of Kavala Gulf covering almost the entire area with the highest touristic activity. During specific time periods, when certain combinations of wind parameters (low wind speed) and tidal amplitudes (high tides) are present, relatively large amounts of microplastics in the surface layer are transported outside the study area, mainly during winter months due to the surface hydrodynamic circulation pattern.

The seasonal increase in microplastics concentration is related clearly to the seasonal increase of the population in the area and therefore to the effluent quantities. Interesting is the fact that the dispersion pattern of microplastics in the bottom layer, at the center of the gulf, is related to vertical fluxes, especially the anticyclonic flows that tend to retain the water at higher depths. The results are in accordance with a similar study that presents the first direct observation of different 
concentrations of plastic between a cyclonic and an anticyclonic mesoscale eddy (Brach et al., 2018, [58]).
This is an Open Access article distributed under the terms of the Creative Commons Attribution License

\section{References}

1. Conley, K., Clum, A., Deepe, J., Lane, H., Beckingham, B., "Wastewater treatment plants as a source of microplastics to an urban estuary: removal efficiencies and loading per capita over one year", Water Res. X 3, 100030 (2019).

2. van Wezel, A., Caris, I, Kools, S.A., "Release of primary microplastics from consumer products to wastewater in the Netherlands", Environ Toxicol Chem, 35(7), pp:1627-312016 Jul.

3. Morét-Ferguson, S., Law, K.L., Proskurowski, G., Murphy, E.K., Peacock, E.E., Reddy, C.M., "The size, mass, and composition of plastic debris in the western North Atlantic Ocean", Mar. Pollut. Bull. 60, pp:1873-1878, (2010).

4. Martins, J., Sobral, P., "Plastic marine debris on the Portuguese coastline: a matter of size?", Mar. Pollut. Bull. 62 (12), pp:26492653, (2011).

5. Lee, R.F., Sanders, D.P., "The amount and accumulation rate of plastic debris on marshes and beaches on the Georgia coast", Mar. Pollut. Bull. 91 (1), pp:113-119 (2015).

6. Suaria, G., Melinte-Dobrinescu, M.C., Ion, G., Aliani, S., "First observations on the abundance and composition of floating debris in the North-western Black Sea”, Mar. Environ. Res. 107, pp:45-49, (2015).

7. G7 Germany, Leaders' Declaration G7 Summit, 7-8 June 2015. G7 Germany, Schloss Elmau, Germany pp:23, (2015).

8. GESAMP, "Sources, Fate and Effects of Microplastics in the Marine Environment: Part Two of a Global Assessment", Rep. Stud. GESAMP 93. IMO, FAO, UNESCO-IOC, UNIDO, WMO, IAEA, UN, UNEP, UNDP Joint Group of Experts on the Scientific Aspects of Marine Environmental Protection, Rome, Italy pp:221, (2016).

9. UNEP, "Marine Plastic Debris and Microplastics - Global Lessons and Research to Inspire Action and Guide Policy Change", United Nations Environment Program, Nairobi, Kenya pp:274, (2016).

10. Cui, R., Kim, S.W., An, Y.J., "Polystyrene nanoplastics inhibit reproduction and induce abnormal embryonic development in the freshwater crustacean Daphnia galeata", Sci. Rep. 7, pp:12095, (2017).

11. Gray, A.D., Weinstein, J.E., "Size and shape dependent effects of microplastic particles on adult daggerblade glass shrimp, Palaemonetes pugio", Environ. Toxicol. Chem., (2017).

12. Bergami, E., Pugnalini, S., Vannuccini, M.L., Manfra, L., Faleri, C., Savorelli, F., Dawson, K.A., Corsi, I., "Long-term toxicity of surface-charged polystyrene nanoplastics to marine planktonic species Dunaliella tertiolecta and Artemia franciscana”, Aquat. Toxicol., 189, pp:159-169 (2017).

13. Ziajahromi, S., Kumar, A., Neale, P.A., Leusch, F.D.L., "Environmentally relevant concentrations of polyethylene microplastics negatively impact the survival, growth and emergence of sediment-dwelling invertebrates", Environ. Pollut., 236, pp:425431, (2018).

14. Farrell, P., Nelson, K., "Trophic level transfer of microplastic: Mytilus edulis (L.) to Carcinus maenas (L.)", Environ. Pollut., 177, pp:1-3, (2013)

15. Velzeboer, I., Kwadijk, C.J.A.F., Koelmans, A.A., "Strong sorption of PCBs to nanoplastics, microplastics, carbon nanotubes, and fullerenes", Environ. Sci. Technol., 48, pp:4869-4876, (2014)

16. Hüffer, T., Weniger, A.K., Hofmann, T., "Sorption of organic compounds by aged polystyrene microplastic particles", Environ. Pollut., 236, pp:218-225, (2018).

17. Fang, S., Yu,W., Li, C., Liu, Y., Qiu, J., Kong, F., "Adsorption behavior of three triazole fungicides on polystyrene microplastics", Sci. Total Environ., 691, pp:1119-1126, (2019).

18. Tourinho, P.S., Ko`cí, V., Loureiro, S., van Gestel, C.A.M., "Partitioning of chemical contaminants to microplastics: Sorption mechanisms, environmental distribution and effects on toxicity and bioaccumulation", Environ. Pollut., 252, 1246-1256, (2019).

19. Chua, E.M., Shimeta, J., Nugegoda, D., Morrison, P.D., Clarke, B.O., "Assimilation of polybrominated diphenyl ethers from microplastics by the marine amphipod, Allorchestes compressa", Environ. Sci. Technol., 48, pp:8127-8134, (2014).
20. Gandara E Silva, P.P., Nobre, C.R., Resa e, P., Pereira, C.D.S., Gusmão, F., "Leachate from microplastics impairs larval development in brown mussels", Water Res., 106, pp:364-370, (2016).

21. Chen, Q., Yin, D., Jia, Y., Schiwy, S., Legradi, J., Yang, S., Hollert, H., "Enhanced uptake of BPA in the presence of nanoplastics can lead to neurotoxic effects in adult zebrafish", Sci. Total Environ., 609, pp:1312-1321, (2017).

22. Lu, K., Qiao, R., An, H., Zhang, Y., "Influence of microplastics on the accumulation and chronic toxic effects of cadmium in zebrafish (Danio rerio)", Chemosphere, 202, pp:514-520, (2018).

23. Banaee, M., Soltanian, S., Sureda, A., Gholamhosseini, A., Haghi, B.N., Akhlaghi, M., Derikvandy, A., "Evaluation of single and combined effects of cadmium and micro-plastic particles on biochemical and immunological parameters of common carp (Cyprinus carpio)", Chemosphere, 236, 124335, (2019).

24. Bradney, L., Wijesekara, H., Palansooriya, K.N., Obadamudalige, N., Bolan, N.S., Ok, Y.S., Rinklebe, J., Kim, K.H., Kirkham, M.B., "Particulate plastics as a vector for toxic trace-element uptake by aquatic and terrestrial organisms and human health risk", Environ. Int., 131, pp:104937, (2019).

25. Galgani, F., Hanke, G., Werner, S., Oosterbaan, L., Nilsson, P., Fleet, D., Kinsey, S., Thompson, R.C., van Franeker, J., Vlachogianni, Th., Scoullos, M., Veiga, J.M., Palatinus, A., Matiddi, M., Maes, T., Korpinen, S., Budziak, A., Leslie, H., Gago, J., Liebezeit, G., "Guidance on Monitoring of Marine Litter in European Seas", Scientific and Technical Research series, Luxembourg: Publications Office of the European Union, (2013).

26. GESAMP, "Sources, fate and effects of microplastics in the marine environment: a global assessment", Joint Group of Experts on the Scientific Aspects of Marine Environmental Protection). Rep. Stud. GESAMP No. 90, pp:96, (2015).

27. Browne, M.A., Crump, P., Niven, S.J., Teuten, E., Tonkin, A., Galloway, T., Thompson, R., "Accumulation of microplastic on shorelines worldwide: sources and sinks", Environ. Sci. Technol.,45, pp: 9175-9179, (2011).

28. GESAMP, 99: "Guidelines for the Monitoring and Assessment of Plastic Litter in the Ocean", Reports and Studies GESAMP, (2019).

29. Kim, I-S., Chae, D-H., Kim, S-K., et al., "Factors influencing the spatial variation of microplastics on high-tidal coastal beaches in Korea", Archives of Environmental Contamination and Toxicology 69, pp:299-309, (2015).

30. Kukulka, T., Proskurowski, G., Moret-Ferguson, S., et al., "The effect of wind mixing on the vertical distribution of buoyant plastic debris", Geophysical Research Letters 39: L07601, (2012)

31. Liubartseva, S., Coppini, G., Lecci, R., et al., "Regional approach to model-ling the transport of floating plastic debris in the Adriatic Sea”, Marine Pollution Bulletin 103 pp:115-127, (2016).

32. Hodges, B.R., and Dallimore, C., "Estuary, Lake and Coastal Ocean Model: ELCOM. v2.2 Science Manual", Centre for Water Research Contract Research Group Technical Report, (2006).

33. Andrady, A. L., "Microplastics in the marine environment", Mar.Pollut. Bull.,62(8), pp:1596-1605, (2011).

34. Besseling, E., Quik, J.T., Sun, M., et al., "Fate of nano-and microplastic in freshwater systems: A modeling study", Environmental Pollution 220 pp:540-548, (2017).

35. Herrera, A., Asensio, M., Martínez, I., et al., "Microplastic and tar pollution on three Canary Islands beaches: An annual study", Marine Pollution Bulletin. 129 pp:494-502, (2017).

36. Zhang, K., Su, J., Xiong, X., et al., "Microplastic pollution of lakeshore sediments from remote lakes in Tibet plateau, China", Environmental Pollution 219, pp:450-455, (2016).

37. Underwood, A., Chapman, M., Browne, M.A., "Some problems and practicalities in design and interpretation of samples of microplastic waste", Analytical Methods., 9 pp:1332-1345, (2017).

38. O’Donncha, F., Hartnett, M., Nash, S., Ren, L., Ragnoli, E., "Characterizing observed circulation patterns within a bay using HF radar and numerical model simulations", Journal of Marine Systems.,142, pp:96-110, (2015). 
39. Lusher, A., McHugh, M., Thompson, R., "Occurrence of microplastics in the gastrointestinal tract of pelagic and demersal fish from the English Channel", Marine pollution bulletin.,67 pp:94-99, (2013).

40. Alomar, C., Estarellas, F., Deudero, S.., "Microplastics in the Mediterranean Sea: deposition in coastal shallow sediments, spatial variation and preferential grain size", Marine environmental research.,115, pp:1-10, (2016).

41. Fischer, V., Elsner, N.O., Brenke, N., Schwabe, E., Brandt, A., "Plastic pollution of the Kuril-Kamchatka Trench area (NW pacific)", Deep Sea Research Part II: Topical Studies in Oceanography, 111, pp:399-405, (2015).

42. Moriarty, M., Pedreschi, D., Stokes, D., Dransfeld, L., Reid, D., "Spatial and temporal analysis of litter in the Celtic Sea from Groundfish Survey data: Lessons for monitoring", Marine pollution bulletin, (2016).

43. Atwood E., Falcieri F. M., Piehl S., Bochow M., Matthies M, Franke J., Carniel S., Sclavo M., Laforsch C., Siegert F., "Coastal accumulation of microplastic particles emitted from the Po River, Northern Italy: Comparing remote sensing and hydrodynamic modelling with in situ sample collections", Marine Pollution Bulletin, Volume 138, pp:561-574, (2019).

44. Sylaios, G., Kamidis, N., Stamatis, N., "Assessment of trace metals contamination in the suspended matter and the sediments of a semienclosed Mediterranean Gulf', Soil Sediment Contam Int J21(6), pp;673-700, (2012).

45. Sylaios, G., "Meteorological influence on the surface hydrographic patterns of the North Aegean Sea", Oceanologia, 53 (1), pp:1-24, (2011).

46. Hodges, B. and Dallimore, C. "ELCOM Science Manual. CWR", University of Western Australia, Crawley, (2010).

47. Botelho, D. and Imberger, J., "Down-Scaling Model Resolution to Illuminate the Internal Wave Field in a Small Stratified Lake", Journal of Hydraulic Engineering (ASCE), 133, pp:1206-1218, (2007).

48. Laval, B.E., Imberger, J. and Findikakis, A.N., "Dynamics of a large tropical lake: Lake Maracaibo", Aquatic Sciences, (2005).

49. Laval, B.E., Imberger, J. and Findikakis, A.N., "Mass transport between a semi-enclosed basin and the ocean: Maracaibo system",
Journal of Geophysical Research (Oceans), 108 (C7) pp:3236, (2003).

50. Morillo, S., Imberger, J., Antenucci, J.P. and Woods, P., "Influence of wind and lake morphometry on the interaction between two rivers entering a stratified lake", Journal of Hydraulic Engineering, ASCE, 134(11), pp:1579-1589, (2008).

51. Romero, J.R., Imberger, J., "Effect of a flood underflow on reservoir water quality-data and 3D modeling", Arch.Hydrobiol. 162, pp:69$86,2003$.

52. Romero, J.R., Antenucci, J.P. and Imberger, J., "One- and threedimensional biogeochemical simulations of two differing reservoirs", Ecological Modelling, 174(1-2), pp:143-160, (2004).

53. Yeates, P., Okely, P., Dallimore, C., Antenucci, J., Hipsey, M. and Imberger, J., "Three-dimensional modelling of a seawater desalination plant discharge into Cockburn Sound, Western Australia", Proceedings of the Fourth International Conference on Asian and Pacific Coasts, September 21-24 2007, Nanjing, China. 811-814, (2007).

54. Kokkos, N., Sylaios, G., "Simulation of the three-dimensional hydrodynamic circulation in north Aegean Sea using ELCOM model", $10^{\text {th }}$ Panhellenic Symposium on Oceanography and Fisheries, Athens (2012)

55. Sylaios, G., Kamidis, N., Anastasiou, S., Tsihrintzis, V.A., "Hydrodynamic response of Thassos Passage (N. Aegean Sea) to Nestos River discharge and meteorological forcing", Continental Shelf Research 59, pp:37-51, (2013).

56. Anastasiou, S., Sylaios, G., "Description of wave climate characteristics and hydrodynamic circulation in the Nestos River Delta area -Application, validation and coupling of wave and hydrodynamic model", $10^{\text {th }}$ Panhellenic Symposium on Oceanography and Fisheries, Athens (2012).

57. Kamidis, N., Sylaios, G. \& Tsihrintzis, V.A., "Modeling the Nestos River plume dynamics using ELCOM", Desalination and Water Treatment, 33 pp:22-35, (2011).

58. Brach, L., Deixonne, P., Bernard, M., et al., "Anticyclonic eddies increase accumulation of microplastic in the North Atlantic subtropical gyre", Marine Pollution Bulletin 126, pp:191-196, (2018) 